\title{
DIRECT GENOTYPING OF TOXOPLASMA GONDII IN BLOOD SAMPLES FROM PREGNANT WOMEN IN JAZAN, SAUDI ARABIA
}

\author{
By \\ AMANY M. EIDA \\ Department of Parasitology ${ }^{1,2}$, Faculty of Medicine, Suez Canal University ${ }^{1}$, Egypt, \\ and Jazan University², Saudi Arabia (Email: amanyeida2@hotmail.com)

\section{Abstract} \\ Toxoplasma gondii (T. gondii) is divided three main clonal lineages designated as type I, II, \\ and III and atypical genotypes were also detected. The distribution of $T$. gondii genotypes varied \\ from one geographic area to another. This study characterized of $T$. gondii isolates from preg- \\ nant women in Jazan. Genetic analysis of the GRA6-coding fragment was performed for $T$. \\ gondii genotyping using PCR-RFLP method. The seropositive for Toxoplasma-specific antibod- \\ ies were determined using ELISA and were $27.9 \%$ in pregnant women in Saudi Arabia. Women \\ seropositive for Toxoplasma $\operatorname{IgG} \& \operatorname{IgM}(\mathrm{GI}=30)$ and for specific $\mathrm{IgG}(\mathrm{GII}=30)$ were included. \\ Among pregnant women, $83.3 \%$ of GI (women seropositive for IgG and $\operatorname{IgM}$ ) and $90 \%$ of GII \\ (women seropositive for $\mathrm{IgG}$ ) were asymptomatic and observed clinical symptoms were fever \\ $(\mathrm{n}=4)$ and cachexia $(\mathrm{n}=2)$ and lymphadenopathy $(\mathrm{n}=1)$. GRA6-nested PCR was positive in 8 \\ blood samples (13.3\%), 5 of GI \& 3 of GII seropositive women. RFLP analysis showed the de- \\ tection of genotype I in 8 samples with no cases coinciding to pattern of type II or type III.
}

Key words: Saudi Arabia, Jazan, Pregnant women $T$. gondii, genotypes, GRA6, PCR-RFLP.

\section{Introduction}

Toxoplasma gondii ( $T$. gondii) is an apicomplexan parasite that is an important protozoan in human and distributed widely in the world (Hill and Dubey, 2002). Human infection occurs by ingesting food and water contaminated with oocysts from cat feces or by ingesting undercooked meat containing cysts. In acute of infection, the $T$. gondii tachyzoite multiplies rapidly within the parasitophorous vacuole. In chronic infection, $T$. gondii forms tissue cysts in the muscles and brain and continue to divide slowly (Montoya and Liesenfeld, 2004; Dubey, 2009). One-third of human population was observed $T$. gondii seropositive (Tenter et al, 2000). Most cases of Toxoplasma infections in adults are asymptomatic, however number of patients experience lymphadenophathy and/or ocular toxoplasmosis in adults. Acquired Toxoplasma infection during pregnancy may lead to congenital disorder in the newborn (Weiss et al, 2009). In immunocompromised patients, toxoplasma infection may lead genotype to reactivation of $T$. gondii cyst in the brain, encephalitis (Abgrall et al, 2001).
Toxoplasma gondii was described as 3 clonal lineages, named types I, II, and III. $T$. gondii I is virulent, whereas types II \& III are avirulent (Sibley and Ajioka, 2008). Virulence of genotype I strains may be due to overstimulation of a Th1 immune response and led to pathogenic changes in involved tissues (Mordue et al, 2001). Genotypes not related to three main lineages were considered atypical or exotic strains (Dardé, 2008). Atypical strains show various virulences i.e., highly virulent, intermediate and non-virulent phenotype (Grigg and Suzuki, 2003; Dardé, 2008). Genotype I strains was seen in immunocompromised patients including in AIDS and recurrent ocular toxoplasmosis (Howe and Sibley, 1995; Grigg and Boothroyd, 2001). In human toxoplasmosis, there is debate about the correlation between $T$. gondii genotype and disease consequences (Boothroyd and Grigg, 2002; Saeij et al, 2005). The investigation of genetic diversity of $T$. gondii isolates is insufficient in human. GRA6 PCR-RFLP technique could easily characterize three different groups of $T$. gondii strains and atypical genotypes (Owen and Trees, 1999; Fazaeli et al, 2000). 
In Saudi Arabia, T. gondii is zoonotic endemic parasite in man, animals and birds (Al-Harthi et al, 2006; Sand and Al-Ghabban, 2007). But, little data about $T$. gondii genotypes was reported (Elamin et al, 2014).

In present study, GRA6 PCR-RFLP technique was performed for characterization of $T$. gondii isolates from pregnant women.

\section{Subjects, Materials and Methods}

The present study was conducted at the Parasitology Laboratory, Faculty of Medicine, Jazan University. Peripheral blood was collected aseptically from 226 pregnant women in outpatient clinic, Jazan General Hospital from December 2014 to May 2015. For Toxoplasma antibodies $5 \mathrm{ml}$ of venous blood was collected and serum was separated by centrifugation at $3000 \mathrm{rpm}$ for $10 \mathrm{~min}$. at room temperature. Toxoplasma-specific IgG \& IgM were determined by using ELISA Kits (Biocheck Inc., CA, USA) according the manufacturer's protocol.

Sixty seropositive pregnant women were only included and divided into 2 groups: GI: 30 women seropositive for both Toxoplas$m a$-specific IgM \& IgG. GII: 30 women seropositive for specific IgG, but without IgM antibodies (Montoya and Remington, 2008).

The remaining whole blood was frozen at $20^{\circ} \mathrm{C}$ until transferred to Egypt for DNA extraction followed by nested PCR. Multiplex PCR was done to amplify the coding region of the GRA6 gene (Lecordier et al, 1995). Nested PCR was done at Biotechnology Center, Ain Shams University. Genomic DNA was extracted from anti-coagulated blood samples using Puregene Kit (Gentra Systems Inc, USA) according to manufacturer's protocol. Oral consent was taken from women and clinical symptoms were registered.

Genotype analysis: Primers used for amplification of the coding region of the GRA6 gene are listed (Tab. 1; Zakimi et al, 2006). Briefly, first-round PCR was done using 25 $\mu 1$ reaction volume of $12.5 \mu 1$ DreamTaq ${ }^{\circledR}$ Green Master Mix (Fermentas, USA), 0.25 $\mu \mathrm{l}$ forward external primer, $0.25 \mu \mathrm{l}$ reverse external primer, $5 \mu 1$ DNA extract $\& 7 \mu 1$ nuclease-free water. Amplification was done in a first cycle using the cycling conditions: Denaturation at $94^{\circ} \mathrm{C}$ for $5 \mathrm{~min}, 35$ cycles of denaturation at $94^{\circ} \mathrm{C}$ for $30 \mathrm{~s}$, annealing at $54^{\circ} \mathrm{C}$ for $60 \mathrm{~s}$, and extension at $72^{\circ} \mathrm{C}$ for $90 \mathrm{~s}$, and then extension step at $72^{\circ} \mathrm{C}$ for $7 \mathrm{~min}$. A second amplification was performed using $1 \mu \mathrm{l}$ of 1:10 diluted PCR products in nuclease-free water from the first amplification reaction. A second-round PCR was carried out in a reaction mixture consisting of $25 \mu \mathrm{l}$ of DreamTaq ${ }^{\circledR}$ Green Ma-ster Mix (Fermentas, USA), $0.5 \mu$ of forward internal primer, $0.5 \mu l$ of reverse internal primer, $10 \mu l$ of diluted PCR product and $14 \mu \mathrm{l}$ of nuclease-free water. The steps of PCR amplification was done using the following cycling condition: An initial denaturation at $94^{\circ} \mathrm{C}$ for $5 \mathrm{~min}, 35$ cycles of denaturation at $94^{\circ} \mathrm{C}$ for $30 \mathrm{~s}$, annealing at $60^{\circ} \mathrm{C}$ for $60 \mathrm{~s}$, and extension at $72^{\circ} \mathrm{C}$ for $90 \mathrm{~s}$, and then a 7 -min extension step at $72^{\circ} \mathrm{C}$. The $2 \%$ agarose gel was used to analyze amplified PCR products and molecular weight marker (100 base pair DNA ladder, Bioron, Germany). Positive DNA control included in each PCR set was extracted from $T$. gondii RH strain (gift from Medical Research Institute, Alexandria) and a negative control was nuclease-free water. Toxoplasma control positive DNA template was prepared (Lin et al, 2000). Tachyzoites acquired from peritoneal lavage of experimentally inoculated mice washed and resuspended in PBS, $\mathrm{pH}$ 7.4. Tachyzoites were incubated at $95^{\circ} \mathrm{C}$ for 10 minutes for protein denaturing and to release DNA.

Table 1: Primers used in nested PCR for detection of Toxoplasma gondii

\begin{tabular}{|lcc|}
\hline \multicolumn{2}{|c|}{ Primer sequences } & Target \\
\hline & External primer \\
Forward & 5'-GGC AAA CAA AAC GAA GTG-3' GRA6 gene \\
Reverse & 5'-CGA CTA CAA GAC ATA GAG TG-3' \\
Internal primers \\
Forward & 5'-GTA GCG TGC TTG TTG GCG AC-3' \\
Reverse & 5'-TAC AAG ACA TAG AGT GCC CC-3' \\
\hline
\end{tabular}


RFLP analysis: To characterize $T$. gondii genotypes in positive samples. PCR products were digested with MseI (Fast Digest ${ }^{\circledR}$ Tru 1I, USA) following manufacturer's protocol. Briefly, $10 \mu \mathrm{l}$ of PCR product was digested for $1 \mathrm{~h}$ at $37^{\circ} \mathrm{C}$ with $1 \mathrm{U}$ of MseI. Digested products were visualized on $2 \%$ agarose gels stained with ethidium bromide $(0.5 \mu \mathrm{g} / \mu \mathrm{l})$ after UV trans-illumination. PCR amplified product of $T$. gondii $\mathrm{RH}$ strain (type I) was used as a control. Genotyping of $T$. gondii strain was determined according to the restriction pattern (Fazaeli et al, 2000).

\section{Results}

In present study, 63 of 226 pregnant women $(27.9 \%)$ were seropositive for Toxoplas-

Table 2: Genotype analysis by GRA6-nested PCR restriction fragment length polymorphism and clinical symptoms in T. gondii seropositive pregnant women

\begin{tabular}{|c|c|c|c|}
\hline Pregnant women (8) & clinical symptoms & PCR-RFLP & Toxoplasma genotype \\
\hline G I (5) & cachexia (2) & + & genotype-I \\
IgG, IgM (+) & fever (2) & + & genotype-I \\
& Lymphadenopathy(1) & + & genotype-I \\
GII (3) & fever (2) & + & genotype-I \\
IgG (+) only & no symptoms(1) & + & genotype-I \\
\hline
\end{tabular}

NA preparations from 8 seropositive pregnant women (13.3\%) yielded products with expected size using nested PCR of coding region of GRA6 (Tab. 2). Eight pregnant women samples ( 5 in GI \& 3 in GII) belonged to $T$. gondii genotype I, none of positive samples belonged to type II or III (Fig. 1).

\section{Discussion}

In Arab countries, toxoplasmosis among women ranged from 22.5 to $37.4 \%$ in Saudi Arabia (Shoura et al, 1973; Abbas et al, 1986), 37.5\% in Libya (Kassem and Morsy, 1991), 37\% in Jordan (Morsy and Michael, 1980), 95.5\% in Kuwait (Behbehani and AlKarmi, 1980) and in Egypt, pregnant women $22.2 \%$ and non-pregnant ones $20 \%$ showed T. gondii antibodies (Saleh et al, 2014).

No doubt, genetic diversity of $T$. gondii is more complicated (Lehmann et al, 2006). However, T. gondii genotype data in humans is still limited. This could be explained by transient nature of $T$. gondii organism in the blood (Holliman, 2009). Identification of $T$. $m a$-specific antibodies. Among 226 women, $30(13.3 \%)$ were seropositive for Toxoplas$m a$-specific $\operatorname{IgG} \& \operatorname{IgM}$ and 33 (14.6\%) were seropositive for IgG with no IgM. Sixty women (30/each) were only included in study. The major pregnant women showed asymptomatic, $83.3 \%$ of GI (women seropositive for $\operatorname{IgG} \& \operatorname{IgM}$ ) and $90 \%$ of GII (IgG seropositive) were asymptomatic. The asymptomatic women came to antenatal care for Toxoplasma screening during pregnancy.

Seven seropositive pregnant women complained clinical symptoms, fever and cachexia in two women, lymphadenopathy in 1 women of GI and fever in 2 women of GII (Tab. 2). gondii genotype is essential in the congenital infection.

In present study, 8/60 seropositive pregnant women (13.3\%) were positive by GRA6 -nested PCR and evaluated by RFLP analysis of amplified GRA6 products. All cases belonged to type I. This procedure is convenient and avoids the need for previous method of isolation in mice or cell culture (Switaj et al, 2006). The detection of type I agreed with AIDS patients and congenital toxoplasmosis (Lindstrom et al, 2006). Atypical genotypes were reported in immunocompromised patients with toxoplasmosis in sub-Saharan Africa (Ajzenberg et al, 2009). In Egypt, GRA6-nested PCR RFLP of T. gondii infected patients showed typical genotype I (Tolba et al, 2014). T. gondii genotype I alone or association with genoty- pe II or III was reported in 13 infected patients by multilocus-nested PCR technique (Boughattas et al, 2010). Genotyping isolates showed limited genetic diversity of $T$. gondii in man and animal (Wang et al, 2013). 


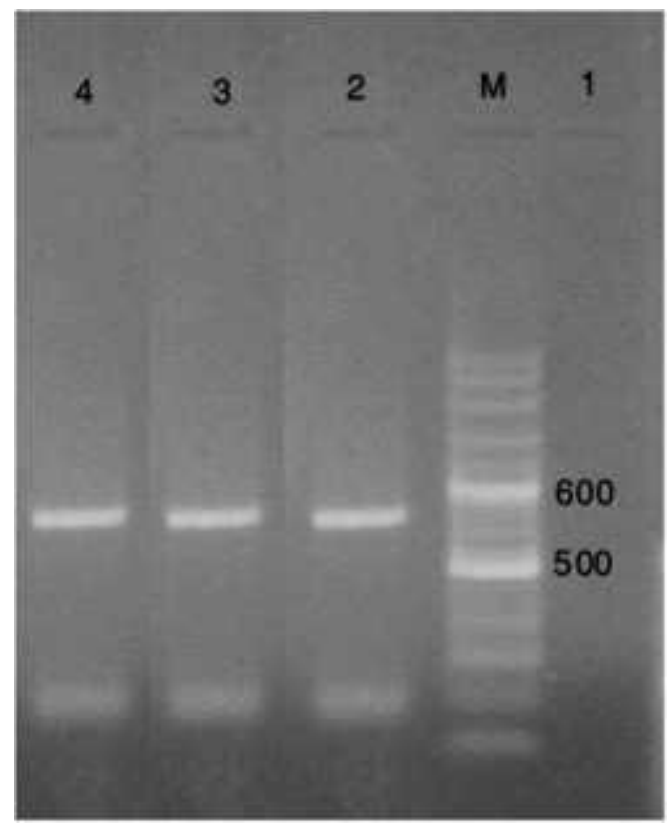

Fig.1: Restriction endonuclease digestion GRA6 -nested PCR product of $T$. gondii with MseI from seropositive blood samples, negative control (Lane1), RH strain (Lane2). Genotype1 (Lane3 \& 4), Size marker = a 100-bp ladder (lane M).

Genotypic of $T$. gondii isolates from rats were $59.1 \%$ of genotype II, $31.8 \%$ of genotype III and $9.1 \%$ were of an unknown genotype in Saudi Arabia. It means that the prevalence of $T$. gondii genotype II \& III was high in rats (Elamin, 2014). The presence of type I in the present study agreed partly to study done in Al-Medina. In this study, genotypes I \& III was in $20.9 \%$ and $21.9 \%$ respectively, while $45.1 \%$ of them belonged to type II. The $12.1 \%$ belonged to atypical genotypes (Abd El-Aal et al, 2010). In contrary, type II and atypical strains were reported in sandcats in Egypt and Qatar (Dubey et al, 2010). Type II \& III strains were reported in Iranian infected animals (Fazaeli et al, 2000). In Egypt, T. gondii clonal types II \& III were reported in chicken (Dubey et $a l, 2003)$. Atypical strains were found in 3.4 $\%$ of cat isolates (Al-Kappany et al, 2010). In human, genotype II was the most prevalent type detected in $33(87 \%)$ infected female. Genotype I was found in 5(13\%), but not genotype III (Abdel-Hameed and Hassa nein, 2008). This discrepancy could be due to small number of positive cases, or difference in subjects and their life-style. The used cell culture or mice isolated parasite might produce sensitive variations in freque- ncies of that effected different strains. Also, the various hosts could shelter different $T$. gondii genotypes (Elamin, 2014). In general, the deficiency of data on Toxoplasma genotyping in Saudi Arabia makes it hard to give an explanation.

Seven out of eight $T$. gondii nested PCR positive cases showed symptoms $(87.5 \%)$. An elevated frequency of type I strains was also observed among immunocompromised patients with recurrent retinal toxoplasmosis and cerebral disease (Grigg et al, 2001; Vallochi et al, 2005; Switaj et al, 2006). The results could be explained by increased pathogenicity of type I strains (Grigg and Suzuki, 2003). Although no relationship was found between the presence of a specific strain type and the clinical presentation (Ferreira et al, 2008), $T$. gondii genotype I was major virulent type with high level of parasitemia (Howe and Sibley, 1995). But, data of genotypes responsible for the frequent asymptomatic toxoplasmosis is limited.

\section{Conclusion}

Serology and genotyping of $T$. gondii from pregnant women performed directly. GRA6nested PCR RFLP proved to be fast \& highly effective method and could be used directly on clinical specimens to obviate time 
consuming procedures as culture. By GRA6nested PCR RFLP blood samples revealed that $T$. gondii type I is predominant in Saudi Arabian women with different clinical symptoms. Toxoplasmosis \& congenital toxoplasmosis is a worldwide problem. Health education is a must for child-bearing age women to minimize the complications.

\section{References}

Abbas, SA, Basalamah, A, Serebour, F, Alfonso, M, 1986: Toxoplasma gondii antibodies in Saudi women and outcome of congenital infection among new-borne in Saudi Arabia. Saudi Med. J. 7:346-54.

Abd El-Aal, AA, Habib, FA, Sheikh, B, Harak, M, Shalaby, SA, 2010: Toxoplasma genotyping among infected human and animal hosts using PCR-restriction fragment length polymorphism: study in Al-Madinah, Saudi Arabia. Int. J. Hlth. Sci. III:2.

Abdel-Hameed, DM, Hassanein, OM, 2008: Genotyping of Toxoplasma gondii strains from female patients with toxoplasmosis. J. Egypt. Soc. Parasitol. 38, 2:511-20.

Abgrall, S, Rabaud, C, Costagliola, D, 2001: Clinical Epidemiology Group of the French Hospital Database on HIV. Incidence and risk factors for toxoplasmic encephalitis in human immunodeficiency virus infected patients before and during the highly active antiretroviral therapy era. Clin. Infect. Dis. 33:1747-55.

Ajzenberg, D, Year, H, Marty, P, Paris, L, Da lle, F, et al, 2009: Genotype of 88 T. gondii isolates associated with toxoplasmosis in immunocompromised patients and correlation with clinical findings. J. Infect. Dis. 199:1155-67.

Al-Harthi, SA, Jamjoom, MB, Ghazi, HO, 2006: Seroprevalence of $T$. gondii among pregnant women in Makah, Saudi Arabia Umm AlQura University. J. Sci. Med. Engn. 18, 2:21727.

Al-Kappany, YM, Rajendran, C, Abu-Elwafa, SA, Hilali, M, et al, 2010: Genetic diversity of Toxoplasma gondii isolates in Egyptian feral cats reveals new genotypes. J. Parasitol. 96: 1112-4.

Behbehani, K, Al-Karmi, T, 1980: Toxoplasmosis in Kuwait: Detection of $T$. gondii antibodies and distribution \% among inhabitants. Trans. R. Soc. Trop. Med. Hyg. 74:209-12.
Boothroyd, JC, Grigg, ME, 2002: Population biology of Toxoplasma gondii and its relevance to human infection: do different strains cause different disease? Curr. Opin. Microbiol. 5:43844.

Boughattas, S, Ben-Abdallah, R, Siala, E, Souissi, O, et al, 2010: Direct genotypic character ization of Toxoplasma gondii strains associated with congenital toxoplasmosis in Tunisia (North Africa). Am. J. Trop. Med. Hyg. 82: 1041-6.

Dardé, ML, 2008: Toxoplasma gondii, new genotypes and virulence. Parasite 15:366-71.

Dubey, JP, 2009: History of the discovery of the life cycle of Toxoplasma gondii. Int. J. Parasitol. 39:877-82.

Dubey, JP, Graham, DH, Dahl, E, Hilali, M, El-Ghaysh, A, et al, 2003: Isolation and molecular characterization of Toxoplasma gondii from chickens and ducks from Egypt. Vet. Parasitol. 114:89-95.

Dubey, JP, Pas, A, Rajendran, C, Kwok, OC, Ferreira, LR, et al, 2010: Toxoplasmosis in sand cats (Felis margarita) and other animals in the breeding centre for endangered Arabian wildlife in the United Arab Emirates and Al Wabra wildlife preservation, the State of Qatar. Vet. Parasitol. 20:195-203.

Elamin, MH, 2014: Genotyping of Toxoplasma gondii from rats (Rattus rattus) in Riyadh, Saudi Arabia. Korean J. Parasitol. 52, 3:257-61.

Fazaeli, A, Carter, PE, Dardé, ML, Pennington, TH, 2000: Molecular typing of Toxoplasma gondii strains by GRA6 gene sequence analysis. Int. J. Parasitol. 30:637-42.

Ferreira, IM, Vidal, JE, Costa-Silva, TA, Meira, CS, Hiramoto, RM, et al, 2008: Toxoplasma gondii: genotyping of strains from Brazilian AIDS patients with cerebral toxoplasmosis by multilocus PCR-RFLP markers. Exp. Parasitol. 118:221-7.

Grigg, ME, Boothroyd, JC, 2001: Rapid identification of virulent type I strains of the protozoan parasite Toxoplasma gondii by PCRrestriction fragment length polymorphism analysis of the B1 gene. J. Clin. Microbiol. 39:398400.

Grigg, ME, Ganatra, J, Boothroyd, JC, Margolis, TP, 2001: Unusual abundance of atypical strains associated with human ocular toxoplasmosis. J. Infect. Dis. 184:633-9.

Grigg, ME, Suzuki, Y, 2003: Sexual recombination and clonal evolution of virulence in Tox- 
oplasma. Microbes Infect. 5:685-90.

Hill, D, Dubey, JP, 2002: Toxoplasma gondii: transmission, diagnosis and prevention. Clin. Microbiol. Infect. 3:634-40.

Holliman, RE, 2009: Toxoplasmosis. In: Manson's Tropical Diseases, $22^{\text {nd }}$ ed. Elsevier, Lond. Howe, DK, Sibley, LD, 1995: Toxoplasma gondii comprises three clonal lineages: correlation of parasite genotype with human disease. J. Infect. Dis. 172:1561-6.

Kassem, HH, Morsy, TA, 1991: The prevalence of anti-Toxoplasma antibodies among pregnant woman in Benghazi (S.P.L.A.J.), Libya. J. Egypt. Soc. Parasitol. 21, 1:69-74.

Lecordier, L, Moleon-Borodowsky, I, Dubremetz, JF, Tourvieille, B, Mercier, C, et al, 1995: Characterization of a dense granule antigen of Toxoplasma gondii (GRA6) associated to the network of the parasitophorous vacuole. Mol. Biochem. Parasitol. 70:85-94.

Lehmann, T, Marcet, PL, Graham, DH, Dahl, ER, Dubey, JP, 2006: Globalization and the population structure of Toxoplasma gondii. Proc. Natl. Acad. Sci. 103:11423-8.

Lin, MH, Chen, TC, Kuo, TT, Tseng, C C, Tseng, CP, 2000: Real-time PCR for quantitative detection of $T$. gondii. J. Clin. Microbiol. 38, 11:4121-2.

Lindstrom, I, Kaddu-Mulindwa, DH, Kironde, F, Lindh, J, 2006: Prevalence of latent and reactivated Toxoplasma gondii parasites in HIVpatients from Uganda. Acta. Trop. 100:218-22.

Montoya, JG, Liesenfeld, O, 2004: Toxoplasmosis. Lancet 363:1965-76.

Montoya, JG, Remington, JS, 2008: Management of Toxoplasma gondii infection during pregnancy. Clin. Infect. Dis. 47:554-66

Mordue, DG, Monroy, F, La Regina, M, Dinarello, CA, Sibley, LD, 2001: Acute toxoplasmosis leads to lethal overproduction of Th1 cytokines. J. Immunol. 167:4574-84.

Morsy, TA, Michael, SA, 1980: Toxoplasmosis in Jordan. J. Egypt. Soc. Parasitol. 10, 2:457-70.

Owen, MR, Trees, AJ, 1999: Genotyping of Toxoplasma gondii associated with abortion in sheep. J. Parasitol., 85:382-4.

Saeij, JP, Boyle, JP, Boothroyd, JC, 2005: Differences among the three major strains of Toxoplasma gondii and their specific interactions with the infected host. Trends Parasitol. 21:476-81
Saleh, AMA, Ali, HA, Ahmed, SAM, Hosny, S M, Morsy, TA, 2014: Screening of Toxoplasma gondii infection among childbearing age females and assessment of nurses' role in prevention and control of toxoplasmosis. J. Egypt. Soc. Parasitol. (JESP) 44, 2:329- 42

Sand, MM, Al-Ghabban, AJ, 2007: Serological survey on toxoplasmosis among slaughtered sheep and goats in Tabook, Saudi Arabia. J. Egypt Soc. Parasitol. 37, 1:329-40.

Shoura, MA, Morsy, TA, EI Dasouqui, IT, 1973: Toxoplasmin skin tests in Riyadh, Saudi Arabia. J. Trop. Med. Hyg. 76, 10:254.

Sibley, LD, Ajioka, JW, 2008: Population structure of Toxoplasma gondii: clonal expansion driven by infrequent recombination \& selective sweeps. Ann. Rev. Microbiol. 62:329-51. Switaj, K, Master, A, Borkowski, PK, Skrzypczak, M, Wojciechowicz, J, et al, 2006: Association of ocular toxoplasmosis with type I Toxoplasma gondii strains: direct genotyping from peripheral blood samples. J. Clin. Microbiol. 44: 4262-4.

Tenter, AM, Heckeroth, AR, Weiss, LM, 2000: Toxoplasma gondii from animals to humans. Int. J. Parasitol. 30:1217-58.

Tolba, MM, EI-Taweel, HA, Khalil, SS, Hazzah, WA, Heshmat, MG, 2014: Genotype analysis of $T$. gondii strains associated with human infection in Egypt. Parasitol. Res. 113, 4: 15639.

Vallochi, AL, Muccioli, C, Martins, MC, Silveira, C, Belfort, R,Jr, Rizzo, LV, 2005: The genotype of Toxoplasma gondii strains causing ocular. Am. J. Ophthalmol. 139, 2:350-1.

Wang, L, Cheng, HW, Huang, KQ, Xu, YH, Li, YN, et al, 2013: Toxoplasma gondii prevalence in food animals and rodents in different regions of China: isolation, genotyping and mouse pathogenicity. Parasit. Vectors, 6:273-5.

Weiss, LM, Dubey, JP, 2009: Toxoplasmosis: a history of clinical observations. Int. J. Parasitol. 39:895-901.

Zakimi, S, Kyan, H, Oshiro, M, Sugimoto, C, Xuenan, $\mathrm{X}$, et al, 2006: Genetic characterization of GRA6 genes from Toxoplasma gondii from pigs in Okinawa, Japan. J. Vet. Med. Sci. 68:1105-7. 